\title{
Greater glucagon-like peptide-1 responses to oral glucose are associated with lower central and peripheral blood pressures
}

Julie R. Lundgren ${ }^{1,2^{*}}$ (D, Kristine Færch ${ }^{3}$, Daniel R. Witte ${ }^{4,6}$, Anna E. Jonsson², Oluf Pedersen², Torben Hansen², Torsten Lauritzen ${ }^{5}$, Jens J. Holst ${ }^{1,2}$, Dorte Vistisen ${ }^{3}$, Marit E. Jørgensen ${ }^{3}$, Signe S. Torekov ${ }^{1,2^{*+}}$ (D) and Nanna B. Johansen ${ }^{3,6+}$

\begin{abstract}
Background and aim: Cardiovascular diseases (CVDs) are globally the leading cause of death and hypertension is a significant risk factor. Treatment with glucagon-like peptide-1 (GLP-1) receptor agonists has been associated with decreases in blood pressure and CVD risk. Our aim was to investigate the association between endogenous GLP-1 responses to oral glucose and peripheral and central haemodynamic measures in a population at risk of diabetes and CVD.
\end{abstract}

Methods: This cross-sectional study included 837 Danish individuals from the ADDITION-PRO cohort (52\% men, median (interquartile range) age 65.5 (59.8 to 70.7) years, BMI 26.1 (23.4 to 28.5 ) kg/m², without antihypertensive treatment and known diabetes). All participants received an oral glucose tolerance test with measurements of GLP-1 at 0, 30 and 120 min. Aortic stiffness was assessed by pulse wave velocity (PWV). The associations between GLP-1 response and central and brachial blood pressure (BP) and PWV were assessed in linear regression models adjusting for age and sex.

Results: A greater GLP-1 response was associated with lower central systolic and diastolic BP of $-1.17 \mathrm{mmHg}$ (95\% confidence interval $(\mathrm{Cl})-2.07$ to $-0.27 \mathrm{mmHg}, \mathrm{P}=0.011)$ and $-0.74 \mathrm{mmHg}(95 \% \mathrm{Cl}-1.29$ to $-0.18 \mathrm{mmHg}$, $\mathrm{P}=0.009)$, respectively, as well as lower brachial systolic and diastolic $\mathrm{BP}$ of $-1.27 \mathrm{mmHg}(95 \% \mathrm{Cl}-2.20$ to $-0.33 \mathrm{mmHg}, \mathrm{P}=0.008)$ and $-1.00(95 \% \mathrm{Cl}-1.56$ to $-0.44 \mathrm{mmHg}, \mathrm{P}=0.001)$, respectively. PWV was not associated with $G L P-1$ release $(P=0.3)$. Individuals with the greatest quartile of $G L P-1$ response had clinically relevant lower BP measures compared to individuals with the lowest quartile of GLP-1 response (central systolic BP: $-4.94(95 \% \mathrm{Cl}$ -8.56 to -1.31$) \mathrm{mmHg}$, central diastolic BP: $-3.05(95 \% \mathrm{Cl}-5.29$ to -0.80$) \mathrm{mmHg}$, brachial systolic BP: -5.18 (95\% $\mathrm{Cl}-8.94$ to -1.42$) \mathrm{mmHg}$, and brachial diastolic BP: $-2.96(95 \% \mathrm{Cl}-5.26$ to -0.67$) \mathrm{mmHg}$.

Conclusion: Greater glucose-stimulated GLP-1 responses were associated with clinically relevant lower central and peripheral blood pressures, consistent with beneficial effects on the cardiovascular system and reduced risk of CVD and mortality.

Trial registration ClinicalTrials.gov Identifier: NCT00237549. Retrospectively registered 10 October 2005

Keywords: GLP-1, Cardiovascular disease, Central blood pressure, Peripheral blood pressure, Aortic stiffness

\footnotetext{
*Correspondence: Julie.lundgren@sund.ku.dk; torekov@sund.ku.dk

${ }^{\dagger}$ Signe S. Torekov and Nanna B. Johansen contributed equally to this work

1 Department of Biomedical Sciences, Faculty of Health and Medical

Sciences, University of Copenhagen, Blegdamsvej 3B, 2200 Copenhagen

N, Denmark

Full list of author information is available at the end of the article
}

(c) The Author(s) 2019. This article is distributed under the terms of the Creative Commons Attribution 4.0 International License (http://creativecommons.org/licenses/by/4.0/), which permits unrestricted use, distribution, and reproduction in any medium, provided you give appropriate credit to the original author(s) and the source, provide a link to the Creative Commons license, and indicate if changes were made. The Creative Commons Public Domain Dedication waiver (http://creativecommons.org/ publicdomain/zero/1.0/) applies to the data made available in this article, unless otherwise stated. 


\section{Background}

Globally, cardiovascular diseases (CVDs) were the leading cause of death in 2017 [1]. Hypertension is a known risk factor of CVD and it is estimated that over 1 billion people suffers from hypertension [2]. Persons with uncontrolled hypertension are at increased risk of allcause, CVD-specific, heart disease-specific and cerebrovascular disease deaths compared to normotensive persons ( $\mathrm{HR}=1.6,2.2,2.2$ and 3.0, respectively) [3]. In recent clinical trials, treatment with glucagon-like peptide-1 receptor agonists (GLP-1 RAs) decreased cardiovascular morbidity and/or mortality in patients with type 2 diabetes at increased cardiovascular risk $[4,5]$. Further, treatment with GLP-1 RAs decreases blood pressure and increases heart rate [6]. GLP-1 is an important incretin hormone which increases insulin secretion and thereby lowers blood glucose levels. It is secreted from the gastrointestinal tract by enteroendocrine L cells, upon nutritional intake, and is rapidly broken down by the enzyme dipeptidyl peptidase-4 (DPP-4) [7]. Beyond the insulinotropic effects, GLP-1 has numerous other effects including inhibition of glucagon secretion [8], inhibition of gastrointestinal secretion and motility [9] and reduction in appetite and food intake [10].

Chronic low-grade inflammation has been proposed to contribute to development of cardiovascular disease and atherosclerosis [11] and several inflammatory markers have been shown to be reduced by treatment with GLP-1 RA [12]. Based on a study with mice lacking the GLP-1 receptor (GLP-1 $\mathrm{R}^{-/-}$) [13], it has been suggested that endogenous GLP-1 play a role in controlling the cardiovascular system [14]. This study showed that GLP$1 \mathrm{R}^{-/-}$mice exhibited both structural and functional cardiac abnormalities compared to wild type mice. Another study in humans, found that acute GLP-1 infusion in physiological concentrations (corresponding to a postprandial level) did not change systolic blood pressure but did increase heart rate, brachial artery diameter and brachial artery flow velocity [15], indicating a physiologically relevant role of GLP-1 on vascular function.

Treatment studies with supra-physiological pharmacological doses of GLP-1 RAs have shown decreased risk of CVD $[4,5]$ and also a decrease in blood pressure [16] whereas the natural endogenous GLP-1 secretion and association with blood pressure measurements is largely unknown. Therefore, we wished to examine the more long term effects of endogenous GLP-1 response to elaborate on the cardiovascular mechanisms of GLP-1 and to investigate whether a greater endogenous GLP-1 response is associated with lower blood pressure. Hence, the aim of this study was to examine the association between endogenous GLP-1 response to glucose and peripheral and central hemodynamic measures in a large,
Danish cohort of 837 individuals at risk of diabetes and thereby also at risk of cardiovascular disease.

\section{Methods}

This cross-sectional study is part of a large observational cohort study: the ADDITION-PRO study, a longitudinal cohort study of individuals at high risk for diabetes, recruited from Danish primary care. A thorough description of the design can be found in the ADDITION-PRO protocol [17].

In the ADDITION-PRO study, a detailed examination programme was executed during 2009-2011, and 2082 individuals participated. Blood sampling for GLP-1 measurement was performed at three out of four study centres, comprising 1853 individuals. Of those, 252 had known type 2 diabetes and 15 did not fast and did not have an OGTT. Of the remaining 1586 participants, 657 were taking antihypertensive medication and 92 additional participants had missing information on central haemodynamics or GLP-1, leaving 837 individuals available for the present analysis. No individuals were using incretin-based drugs. Of the 837 individuals, 116 were using lipid-lowering drugs, which we allowed in the present analysis.

\section{Peripheral and central haemodynamics}

Brachial blood pressure was measured three times with the participant in a sitting position after $10 \mathrm{~min}$ of rest (Omron M6 comfort, Omron Healthcare, Milton Keynes, UK) and reported as an average. Aortic pulse wave velocity (PWV) and central blood pressure were assessed with the participant in a supine position after $10 \mathrm{~min}$ of rest using a SphygmoCor apparatus (version 8, Atcor Medical, West Ryde, NSW, Australia) and a tonometer, which captured wave forms at the carotid, femoral and radial artery. Using simultaneous ECG monitoring, the time from the $\mathrm{R}$ wave to the arrival of the pulse wave at the carotid and femoral artery, respectively, was captured. An anthropometer (Seca, Medical Scales and Measuring Systems, Hamburg, Germany) was used to measure the distance from the suprasternal point to the carotid artery recording site and from the suprasternal point to the femoral artery recording site to avoid overestimation of the distance. The ratio between the distance and the time defined the PWV. The PWV was measured twice between the right carotid and right femoral artery and in case of a difference of more than $0.5 \mathrm{~m} / \mathrm{s}$, a third measure was taken. It was reported as an average of the two closest measures. Peripheral pressure waveforms assessed at the radial artery were used to estimate central blood pressure [17]. The average of two measures were used. 


\section{Biochemical measures}

A 3-point standard $75 \mathrm{~g}$ oral glucose tolerance test (OGTT) was performed, with blood sampling before $(0 \mathrm{~min})$ and 30 and $120 \mathrm{~min}$ after glucose intake. Plasma glucose was measured using one of two different methods; Hitachi 912 system (Roche Diagnostics, Mannheim, Germany) or Vitros 5600 system (Ortho Clinical Diagnostics, Illkirch Cedex, France). Subsequently, Vitros values were converted to Hitachi values [18]. HbA1c was measured by high-performance liquid chromatography (TOSOH G7, Tokyo, Japan) [18]. Plasma levels of total GLP-1 (intact and metabolites) were measured in EDTA plasma stored at $-80{ }^{\circ} \mathrm{C}$ using RIA with analytical detection limit around $1 \mathrm{pmol} / \mathrm{l}$ and with intra- and interassay coefficients of variation of $6.0 \%$ and $15 \%$. To diminish methodological variances, all samples were analysed after study completion during 2 consecutive months. Furthermore, quality controls and batches for all reagents were identical for all sets [18].

\section{Statistics}

GLP-1 response was defined as the incremental area under the curve (iAUC), from start of the OGTT to 120 min after glucose intake, using the GLP-1 measurements before glucose intake and after 30 and $120 \mathrm{~min}$. Using the trapezoid rule, iAUC was calculated as total area under the curve subtracted the fasting GLP-1 value $\times 120 \mathrm{~min}$ (participants with $\mathrm{iAUC} \leq 0$ are excluded from analyses). Associations between GLP-1 release and central haemodynamics were analysed in separate models using linear regression analysis. Prior to analysis, iAUC for GLP-1(iAUC GLP-1 $_{1}$ ) was $\log _{2}$-transformed to fulfil the requirement of a normal distribution of the model residuals. All analyses were adjusted for age and sex. Analyses of PWV were additionally adjusted for mean blood pressure and heart rate at time of PWV measurement. Additional analyses adjusting for age, sex and either iAUC insulin, fasting plasma glucose, BMI or HOMA-IR were performed for association between iAUC GLP-1 and central and brachial blood pressures. The study population was categorized into quartiles according to the iAUC GLP-1 response and the lowest and highest quartiles were compared with regards to blood pressure measures (adjusting for age and sex). Sub-analysis of the study population was made dividing the population into a normo glucose (fasting glucose $<5.6 \mathrm{mmol} / \mathrm{l}$ ) group and a prediabetes risk (fasting glucose $\geq 5.6 \mathrm{mmol} / \mathrm{l}$ ) group and association to blood pressures were investigated (adjusting for age and sex). Analyses were performed using SAS version 9.4 (SAS Institute, Cary, NC, USA) and figures were created in $\mathrm{R}$ version 3.2.2 (The $\mathrm{R}$ Foundation for
Statistical Computing). A P-value of $<0.05$ was considered significant.

\section{Results}

The 837 individuals included for analysis had a median (interquartile range) age of 65.5 (59.8 to 70.7$)$ years and $47.7 \%$ were women, BMI of 26.1 (23.4 to 28.5$) \mathrm{kg} / \mathrm{m}^{2}$, fasting glucose concentration of 5.9 (5.5 to 6.3$) \mathrm{mmol} / \mathrm{l}$, HbA1c level of 5.6 (5.4 to 5.8) \% and a median blood pressure within the normal range (brachial systolic blood pressure of 130 (118.3 to 142) $\mathrm{mmHg}$ and diastolic blood pressure of 80 (73.3 to 87.0) $\mathrm{mmHg}$ ), Table 1. OGTT responses of GLP-1, glucose and insulin are shown in Fig. 1.

A greater GLP-1 response during the OGTT (iAUC GLP-1) was associated with a lower central systolic $(-1.17 \mathrm{mmHg} ; \mathrm{P}=0.011)$ and diastolic $(-0.74 \mathrm{mmHg}$; $\mathrm{P}=0.009$ ) blood pressure as well as a lower brachial systolic $(-1.27 \mathrm{mmHg} ; \mathrm{P}=0.008)$ and diastolic $(-1.00 \mathrm{mmHg} ; \mathrm{P}=0.001)$ blood pressure. Central pulse pressure and brachial pulse pressure were not significantly associated with GLP-1 secretion, Table 2 and Fig. 2.

A doubling in $\mathrm{iAUC}_{\mathrm{GLP}-1}$ resulted in a non-significant difference in PWV of $-0.04 \mathrm{~m} / \mathrm{s}(\mathrm{P}=0.3)$.

Analyses were adjusted for age and sex and PWV analyses was additionally adjusted for blood pressure and heart rate. The association between GLP-1 response and central and peripheral blood pressure remained significant when adjusting for fasting glucose, iAUC insulin response, and for HOMA-IR (with

\section{Table 1 Characteristics}

\begin{tabular}{lll}
\hline Characteristics & Median & IQR or $\mathbf{n}(\%)$ \\
\hline Age (years) & 65.5 & $(59.8 ; 70.7)$ \\
Women, $\mathrm{n}(\%)$ & 399 & $(47.7)$ \\
BMI $\left(\mathrm{kg} / \mathrm{m}^{2}\right)$ & 26.1 & $(23.4 ; 28.5)$ \\
Fasting plasma glucose $(\mathrm{mmol} / \mathrm{l})$ & 5.9 & $(5.5 ; 6.3)$ \\
HbA1c (\%) & 5.6 & $(5.4 ; 5.8)$ \\
Fasting serum insulin (pmol/l) & 34.0 & $(23.0 ; 51.0)$ \\
Fasting GLP-1 (pmol/l) & 12.0 & $(8.0 ; 15.0)$ \\
Pulse wave velocity (m/s) & 7.6 & $(6.6 ; 8.9)$ \\
Central systolic blood pressure $(\mathrm{mmHg})$ & 120.5 & $(110.3 ; 132.3)$ \\
Central diastolic blood pressure $(\mathrm{mmHg})$ & 78.0 & $(71.5 ; 85.0)$ \\
Central pulse pressure $(\mathrm{mmHg})$ & 41.5 & $(35.5 ; 50.2)$ \\
Brachial systolic blood pressure $(\mathrm{mmHg})$ & 130.3 & $(118.3 ; 142.0)$ \\
Brachial diastolic blood pressure $(\mathrm{mmHg})$ & 80.0 & $(73.3 ; 87.0)$ \\
Brachial pulse pressure $(\mathrm{mmHg})$ & 49.7 & $(41.7 ; 57.7)$ \\
Heart rate (beats/min) & 61.3 & $(55.5 ; 67.8)$ \\
\hline
\end{tabular}

Characteristics of the study population. IQR interquartile range, $B M I$ body mass index, HbA1c glycated haemoglobin, GLP-1 glucagon-like peptide-1 


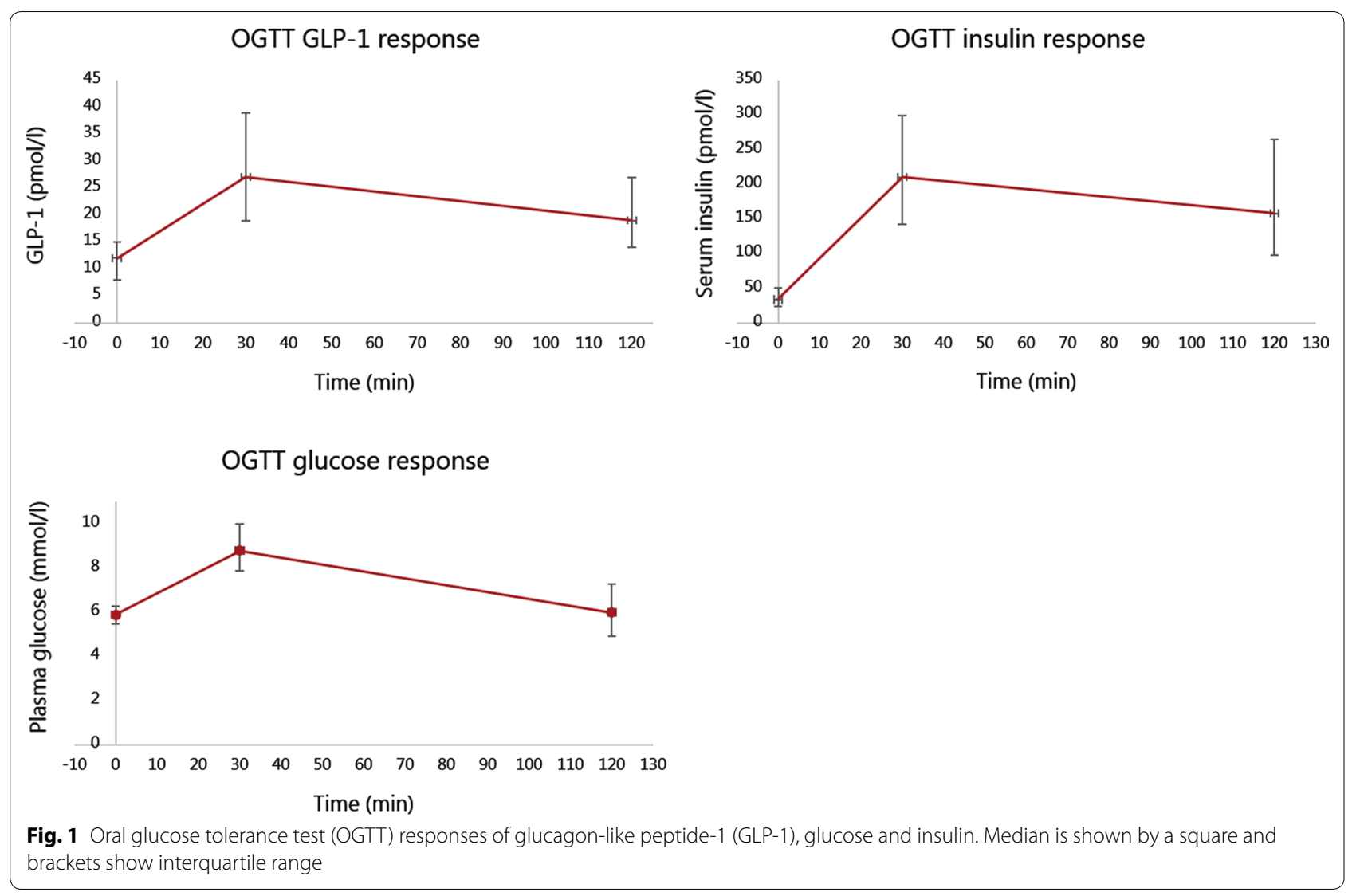

Table 2 Haemodynamic measurements

\begin{tabular}{llll}
\hline Measurement & Estimate $(\mathbf{m m H g})$ & 95\% confidence interval (mmHg) & P value \\
\hline Central systolic blood pressure $^{\mathrm{a}}$ & -1.17 & -2.07 to -0.27 & 0.0109 \\
Central diastolic blood pressure $^{\mathrm{a}}$ & -0.74 & -1.29 to -0.18 & 0.0089 \\
Central pulse pressure $^{\mathrm{a}}$ & -0.43 & -1.03 to 0.17 & 0.2 \\
Brachial systolic blood pressure $^{\mathrm{a}}$ & -1.27 & -2.20 to -0.33 & 0.0081 \\
Brachial diastolic blood pressure $^{\mathrm{a}}$ & -1.00 & -1.56 to -0.44 & 0.0005 \\
Brachial pulse pressure $^{\mathrm{a}}$ & -0.27 & -0.88 to 0.35 & 0.4 \\
Pulse wave velocity $^{\mathrm{b}}$ & -0.04 & -0.13 to 0.04 & 0.3 \\
\hline
\end{tabular}

Estimated difference in blood pressure measurements and PWV for a doubling in iAUC of GLP-1. P-values $<0.05$ are italicized

a Adjusted for age and sex

b Additionally adjusted for heart rate and mean blood pressure during the PWV measurement

the exception of central diastolic blood pressure) (in separate analyses). When adjusting for BMI, the association remained significant for central systolic blood pressure and peripheral diastolic blood pressure, Fig. 2. Sub-analysis of individuals with normal fasting glucose (fasting glucose level $<5.6 \mathrm{mmol} / \mathrm{l}, \mathrm{n}=270$ ) and of individuals with pre-diabetes (fasting glucose level $\geq 5.6 \mathrm{mmol} / \mathrm{l}, \mathrm{n}=567$ ) did not reach statistical significance and there was no significant difference between the groups.
Greater GLP-1 response is associated with $\sim 5 \mathrm{mmHg}$ lower blood pressure compared to individuals with lower GLP-1 response

The participants were divided into quartiles according to their iAUC GLP-1 response. The group with the highest quartile of GLP-1 response was associated with significant lower central systolic $(-4.94(95 \% \mathrm{CI}-8.56$ to -1.31$) \mathrm{mmHg})$ and diastolic $(-3.05(95 \% \mathrm{CI}-5.29$ to -0.80$) \mathrm{mmHg}$ ) blood pressure as well as significant lower brachial systolic $(-5.18(95 \% \mathrm{CI}-8.94$ to -1.42$)$ 


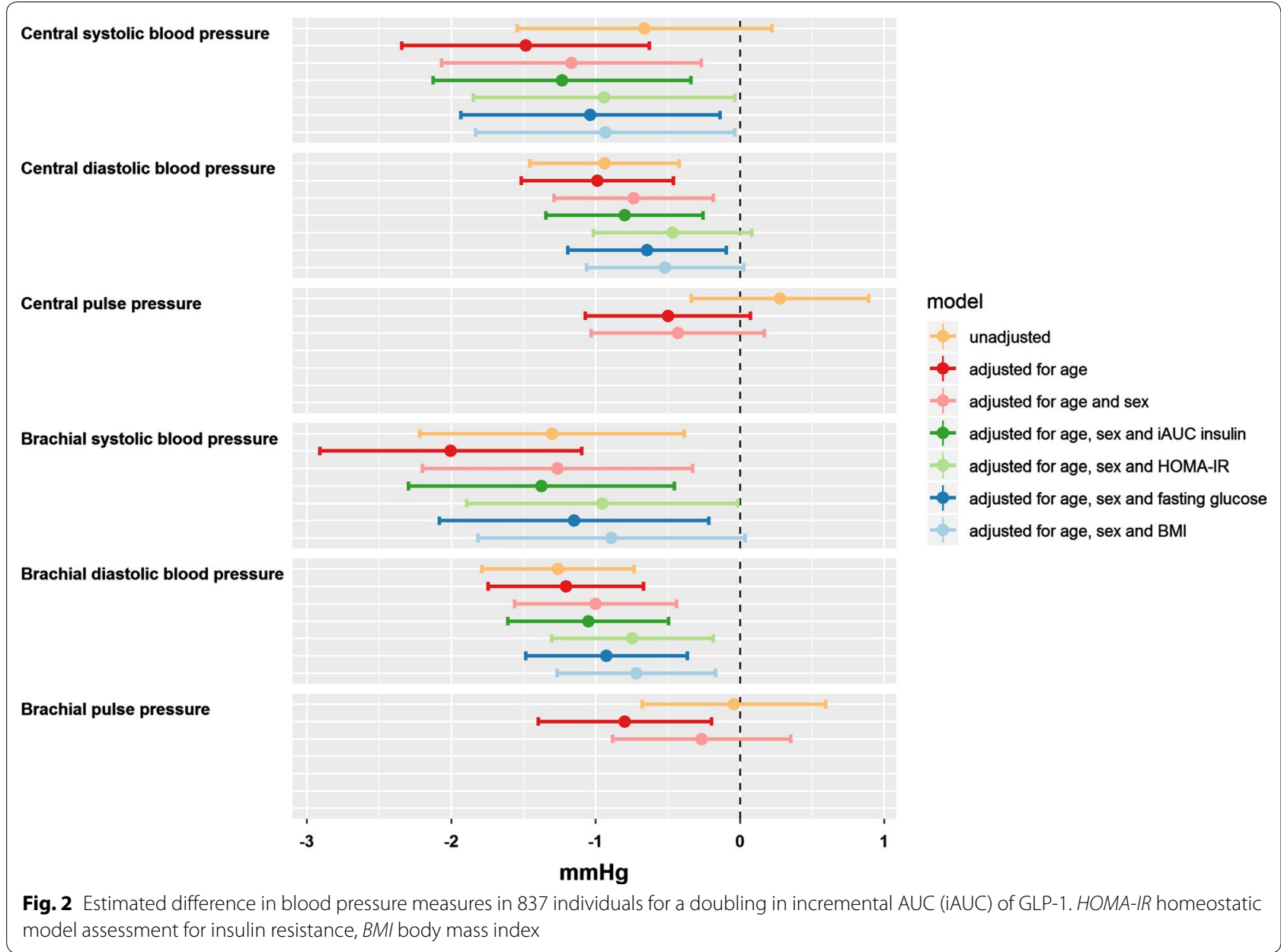

$\mathrm{mmHg})$ and diastolic $(-2.96(95 \% \mathrm{CI}-5.26$ to -0.67$)$ $\mathrm{mmHg}$ ) blood pressure, compared to the group with the lowest quartile of GLP-1 response.

\section{Discussion}

This study of 837 people at risk of diabetes and thereby CVD shows that there is a clinically relevant relationship between greater endogenous GLP-1 hormone response during an OGTT and lower blood pressure measures in a normotensive population. The quartile of individuals with the highest GLP-1 response had a $\sim 5 \mathrm{mmHg}$ lower blood pressure compared to the quartile of individuals with the lowest GLP-1 response. This degree of blood pressure lowering has been associated with lower risk of cardiovascular event, all-cause mortality and cardiovascular mortality. Thus indicating beneficial effects on the cardiovascular system with greater endogenous GLP-1 secretion in agreement with the observations of lower cardiovascular mortality and decreased blood pressure with GLP-1 RA treatment $[4,5,16]$.

\section{Possible mechanisms of blood pressure lowering action of GLP-1 RA}

Several parameters have been proposed to affect the secretion and concentration of GLP-1 including glucose [19], fat [19], bile acids [20], inflammatory markers [21, 22], 3-deoxyglucosone [23] (generated from carbohydrates) and the presence of obesity [24] and type 2 diabetes [18].

We find that there is an association between a greater GLP-1 response during an OGTT and lower central and peripheral blood pressure. Our results remain significant even after adjusting for iAUC insulin, fasting glucose, and for most analyses also for BMI and HOMA-IR, which are all factors known to have an impact on GLP-1 secretion. Interestingly, when dividing participants into quartiles according to their GLP-1 response we found that the group with the highest GLP-1 response was associated with approximately $5 \mathrm{mmHg}$ lower blood pressures compared to the group with the lowest GLP-1 response. Many individuals with obesity and/or type 2 diabetes have decreased GLP-1 secretion $[18,24,25]$ and these 
individuals also often have increased blood pressure [26, 27]. Furthermore, weight loss increases GLP-1 response and decreases blood pressure $[25,28]$. Thus, according to our results, it could be speculated whether the decreased GLP-1 response could contribute to the increased blood pressure in this population. Together with our analyses adjusted for several parameters, this implies that endogenous GLP-1 may have an effect on blood pressure in a dose-response dependent manner with the greater the GLP-1 response the lower the blood pressure as also observed for the dose-response dependently lowering of blood glucose $[29,30]$.

\section{Clinical implications}

We observe that the quartile of individuals with the highest GLP-1 response have a $\sim 5 \mathrm{mmHg}$ lower blood pressure compared to the quartile of individuals with the lowest GLP-1 response. A large meta-analysis found that the degree of blood pressure reduction was proportional to the risk of major cardiovascular disease events, stroke, heart failure, and all-cause mortality [31]. Interestingly, a reduction of $4.5 \mathrm{mmHg}$ in systolic blood pressure has been associated with lower risk of cardiovascular event, all-cause mortality and cardiovascular mortality [32]. Thus our finding of a $5 \mathrm{mmHg}$ difference in blood pressure between GLP-1 response groups is of clinical relevance with regards to mortality. In comparison, DPP-4 inhibitors reduce systolic blood pressure by 2.5$2.8 \mathrm{mmHg}$ [33-35] and GLP-1 RAs reduce systolic blood pressure by $1.2-4 \mathrm{mmHg}[4,5,36]$. GLP-1 RAs $[4,5,37]$ have, furthermore been found to reduce risk of major adverse cardiac events which has not been observed for DPP-4 inhibitors [38-40].

The GLP-1 receptor has been located on endothelial cells in the vasculature [41] and a direct effect of GLP-1 on vascular smooth muscle has also been proposed [42]. This may be one of the mechanisms by which GLP-1 RA treatment decreases blood pressure. Endothelial dysfunction, characterized by reduced nitric oxide (NO) production, is a precursor of atherosclerosis and a risk factor for CVD [43]. GLP-1 treatment promotes vasodilation by production of NO [44]. Insulin has also been shown to induce NO production [45], however, the association in our study remained significant when adjusting the analyses for insulin (see Fig. 2), indicating that GLP-1 works independently of insulin on the blood pressure-lowering mechanism. Infusion of GLP-1 in physiological doses exerted vasodilatory actions, decreased diastolic blood pressure and increased heart rate whereas systolic blood pressure was unchanged in a study of 26 healthy individuals [15]. Furthermore, treatment with GLP-1 RAs have shown to improve arterial stiffness in type 2 diabetes [46], which is augmented by hypertension [47]. Similarly, treatment with DPP-4 inhibitors have shown to improve intima-media thickness [48], arterial stiffness [49] and diastolic dysfunction [50,51], which are all factors associated with blood pressure $[52,53]$. In our study of individuals without diabetes and hypertension we did not find an association between GLP-1 response and PWV (Table 2), a measurement of arterial stiffness, or central pulse pressure (Fig. 2), which is determined by arterial stiffness [47]. To further support the effect of GLP-1 RAs on endothelial cells, liraglutide has also been found to have anti-restenotic effects mediated by endothelial NO [54]. Endothelial cells do not only play a role in NO production, they also influence on the angiogenesis process [55] and liraglutide has been found to promote angiogenesis after stroke [56] opening up for the possibility that GLP-1-based treatment potentially could be applied as a neuroprotective drug as well as a cardioprotective, antihyperglycemic and anti-obesity drug.

\section{Other studies with endogenous GLP-1 levels}

Only few studies have previously analysed the association between endogenous GLP-1 levels and cardiovascular disease. In agreement with our findings, an inverse correlation $(r=-0.26, P=0.0085)$ between GLP-1 secretion and systolic blood pressure was found by Yoshihara et al. [57]. However, active GLP-1 (the levels of which are most often below detection levels of the assays) rather than total GLP-1 was measured in this study of 103 individuals with an ELISA kit. Another study reported a positive association between levels of GLP-1 and coronary artery disease [58]. However blood samples were gathered randomly, i.e. not necessarily in a fasting state, from 303 persons and GLP-1 levels (active GLP-1 and metabolites) were measured by ELISA in serum. Since random blood sampling is a major limitation to the study above comparability to other studies is likely to be difficult. Furthermore, it is worth noting that the specificity, sensitivity, and validity can vary considerably between the ELISA kits available for GLP-1 analyses [59].

\section{Strengths and limitations}

Our physiological study includes more than 800 participants making its size a major strength, outnumbering previous studies $[57,58]$. Total GLP-1 (not active/intact GLP-1) was measured with the use of a well-documented RIA with high specificity and sensitivity [60]. Measuring GLP-1 in this manner provides more information than solely measuring intact GLP-1 as GLP-1 metabolites also are included in the analyses [18]. Because of the rapid metabolism of the hormone, estimation of its secretion must be made with an assay for total GLP-1. A limitation of this study, however, is the cross-sectional design, allowing us to find associations between GLP-1 and 
central and peripheral haemodynamic measures whereas we cannot conclude on causality. However, our findings are in agreement with observations from GLP-1 treatment studies on lowering hypertension and cardiovascular mortality $[4,5]$. Haemodynamic measurements were collected only in a fasting state. Therefore, it was not possible to investigate the acute effects of GLP-1 secretion on blood pressure and PWV. Other studies have found no change [61] or increase [62] in blood pressure after acute infusion of GLP-1. In general, there does not seem to be consensus about whether blood pressure changes during an OGTT. One study found an elevation in systolic blood pressure of more than $4 \mathrm{mmHg}$ after glucose load [63] while other studies find either small increases [64] or no differences [65]. Lastly, our sub-analysis dividing participants into a normal fasting glucose group and a pre-diabetes group did not reveal any significant differences between the groups, which may be due to the lower number of participants in each group.

\section{Conclusion}

We found that greater glucose-stimulated GLP-1 responses were associated with clinically relevant lower central and peripheral blood pressure. Thus, it is likely that endogenous GLP-1 response has a beneficial impact on vascular function, consistent with beneficial effects on the cardiovascular system and reduced risk of CVD and mortality.

\begin{abstract}
Abbreviations
BDBP: brachial diastolic blood pressure; BMI: body mass index; BP: blood pressure; BPP: brachial pulse pressure; BSBP: brachial systolic blood pressure; CDBP: central diastolic blood pressure; $\mathrm{Cl}$ : confidence interval; CPP: central pulse pressure; CSBP: central systolic blood pressure; CVD: cardiovascular disease; DPP-4: dipeptidyl peptidase-4; GLP-1: glucagon-like peptide-1; GLP-1 RA: glucagon-like peptide-1 receptor agonist; HOMA-IR: homeostatic model assessment for insulin resistance; HR: heart rate; iAUC: incremental area under the curve; NO: nitric oxide; OGTT: oral glucose tolerance test; PWV: pulse wave velocity.
\end{abstract}

\section{Acknowledgements}

We would like to thank all the study participants for taking part in this study.

\begin{abstract}
Authors' contributions
Overall manuscript design by JRL and SST. JRL drafted the manuscript with help from SST. Statistical analyses were performed by NBJ and secondary analyses by NBJ and JRL. JRL, KF, SST and NBJ interpreted data. NBJ, DRW, TL and AS designed the ADDITION-PRO study with contribution from $\mathrm{TH}$ and OBP. GLP-1 data was analysed at the laboratory of JJH. All authors contributed to completion of the manuscript including critical revision. All authors read and approved the final manuscript.
\end{abstract}

\section{Funding}

This work was supported by the Tripartite Immunometabolism Consortium (TrIC) Novo Nordisk Foundation (Grant Number NNF15CC0018486) and by the Faculty of Health and Medical Sciences, University of Copenhagen.

\section{Availability of data and materials}

The dataset used and analysed during the current study are available from the corresponding author on request.

\section{Ethics approval and consent to participate}

The ADDITION-PRO study was approved by the Ethical Committee in the Central Danish Region (No. 20000183). Written informed consents were obtained from all participants prior to the examination.

\section{Consent for publication}

Not applicable.

\section{Competing interests}

TL holds shares in Novo Nordisk. All other authors declare that they have no competing interests.

\section{Author details \\ ${ }^{1}$ Department of Biomedical Sciences, Faculty of Health and Medical Sciences, University of Copenhagen, Blegdamsvej 3B, 2200 Copenhagen N, Denmark. \\ ${ }^{2}$ Novo Nordisk Foundation Center for Basic Metabolic Research, University of Copenhagen, Copenhagen, Denmark. ${ }^{3}$ Steno Diabetes Center Copen- hagen, Gentofte, Denmark. ${ }^{4}$ Aarhus University, Aarhus, Denmark. ${ }^{5}$ Institute of Public Health, University of Aarhus, Aarhus, Denmark. ${ }^{6}$ Danish Diabetes Academy, Odense, Denmark.}

Received: 8 July 2019 Accepted: 27 September 2019

Published online: 05 October 2019

\section{References}

1. World Health Organization. Cardiovascular diseases (CVDs). 2017. https ://www.who.int/news-room/fact-sheets/detail/cardiovascular-diseases(cvds). Accessed 9 Sept 2019.

2. World Health Organization. Hypertension. 2019. https://www.who.int/ news-room/fact-sheets/detail/hypertension. Accessed 5 Sept 2019.

3. Zhou D, Xi B, Zhao M, Wang L, Veeranki SP. Uncontrolled hypertension increases risk of all-cause and cardiovascular disease mortality in US adults: the NHANES III Linked Mortality Study. Sci Rep. 2018;8(1):9418.

4. Marso SP, Daniels GH, Brown-Frandsen K, Kristensen P, Mann JFE, Nauck MA, et al. Liraglutide and cardiovascular outcomes in type 2 diabetes. $\mathrm{N}$ Engl J Med. 2016;375(4):311-22.

5. Marso SP, Bain SC, Consoli A, Eliaschewitz FG, Jódar E, Leiter LA, et al. Semaglutide and cardiovascular outcomes in patients with type 2 diabetes. N Engl J Med. 2016;375(19):1834-44.

6. Robinson LE, Holt TA, Rees K, Randeva HS, O'Hare JP. Effects of exenatide and liraglutide on heart rate, blood pressure and body weight: systematic review and meta-analysis. BMJ Open. 2013;3(1):e001986.

7. Mclntosh CHS, Widenmaier S, Kim SJ. Pleiotropic actions of the incretin hormones. Vitamins and hormones. Waltham: Academic Press; 2010. p. 21-79.

8. Orskov C, Holst JJ, Nielsen OV. Effect of truncated glucagon-like peptide-1 [proglucagon-(78-107) amide] on endocrine secretion from pig pancreas, antrum, and nonantral stomach. Endocrinology. 1988;123(4):2009-13.

9. Wettergren A, Schjoldager B, Mortensen PE, Myhre J, Christiansen J, Holst JJ. Truncated GLP-1 (proglucagon 78-107-amide) inhibits gastric and pancreatic functions in man. Dig Dis Sci. 1993;38(4):665-73.

10. Flint A, Raben A, Astrup A, Holst JJ. Glucagon-like peptide 1 promotes satiety and suppresses energy intake in humans. J Clin Invest. 1998;101(3):515-20.

11. Libby P, Ridker PM, Maseri A. Inflammation and atherosclerosis. Circulation. 2002;105(9):1135-43.

12. Liu $H$, Dear $A E$, Knudsen $L B$, Simpson RW. A long-acting glucagon-like peptide-1 analogue attenuates induction of plasminogen activator inhibitor type-1 and vascular adhesion molecules. J Endocrinol. 2009;201(1):59-66.

13. Gros R, You X, Baggio LL, Kabir MG, Sadi AM, Mungrue IN, et al. Cardiac function in mice lacking the glucagon-like peptide-1 receptor. Endocrinology. 2003;144(6):2242-52.

14. Grieve DJ, Cassidy RS, Green BD. Emerging cardiovascular actions of the incretin hormone glucagon-like peptide-1: potential therapeutic benefits beyond glycaemic control? Br J Pharmacol. 2009;157(8):1340-51.

15. Subaran SC, Sauder MA, Chai W, Jahn LA, Fowler DE, Aylor KW, et al. GLP-1 at physiological concentrations recruits skeletal and cardiac muscle microvasculature in healthy humans. Clin Sci (Lond). 2014;127(3):163-70. 
16. Wang B, Zhong J, Lin H, Zhao Z, Yan Z, He H, et al. Blood pressurelowering effects of GLP-1 receptor agonists exenatide and liraglutide: a meta-analysis of clinical trials. Diabetes Obes Metab. 2013;15(8):737-49.

17. Johansen NB, Hansen ALS, Jensen TM, Philipsen A, Rasmussen SS, Jørgensen ME, et al. Protocol for ADDITION-PRO: a longitudinal cohort study of the cardiovascular experience of individuals at high risk for diabetes recruited from Danish primary care. BMC Public Health. 2012;12:1078.

18. Færch K, Torekov SS, Vistisen D, Johansen NB, Witte DR, Jonsson A, et al. GLP-1 response to oral glucose is reduced in prediabetes, screendetected type 2 diabetes, and obesity and influenced by sex: the ADDITION-PRO study. Diabetes. 2015;64(7):2513-25.

19. Elliott RM, Morgan LM, Tredger JA, Deacon S, Wright J, Marks V. Glucagonlike peptide-1 (7-36)amide and glucose-dependent insulinotropic polypeptide secretion in response to nutrient ingestion in man: acute postprandial and 24-h secretion patterns. J Endocrinol. 1993;138(1):159-66.

20. Katsuma S, Hirasawa A, Tsujimoto G. Bile acids promote glucagon-like peptide-1 secretion through TGR5 in a murine enteroendocrine cell line STC-1. Biochem Biophys Res Commun. 2005;329(1):386-90.

21. Ellingsgaard H, Hauselmann I, Schuler B, Habib AM, Baggio LL, Meier DT, et al. Interleukin-6 enhances insulin secretion by increasing glucagon-like peptide-1 secretion from L cells and alpha cells. Nat Med. 2011;17(11):1481-9.

22. Lee Y-S, Jun H-S. Anti-inflammatory effects of GLP-1-based therapies beyond glucose control. Mediat Inflamm. 2016;2016:3094642.

23. Wang F, Song X, Zhou L, Liang G, Huang F, Jiang G, et al. The downregulation of sweet taste receptor signaling in enteroendocrine L-cells mediates 3-deoxyglucosone-induced attenuation of high glucose-stimulated GLP-1 secretion. Arch Physiol Biochem. 2018;124(5):430-5.

24. Muscelli E, Mari A, Casolaro A, Camastra S, Seghieri G, Gastaldelli A, et al. Separate impact of obesity and glucose tolerance on the incretin effect in normal subjects and type 2 diabetic patients. Diabetes. 2008:57(5):1340-8.

25. lepsen EW, Lundgren J, Holst JJ, Madsbad S, Torekov SS. Successful weight loss maintenance includes long-term increased meal responses of GLP-1 and PYY3-36. Eur J Endocrinol. 2016;174(6):775-84. https://doi. org/10.1530/EJE-15-1116.

26. Hall JE, do Carmo JM, da Silva AA, Wang Z, Hall ME. Obesity-induced hypertension: interaction of neurohumoral and renal mechanisms. Circ Res. 2015;116(6):991-1006.

27. Lastra G, Syed S, Kurukulasuriya LR, Manrique C, Sowers JR. Type 2 diabetes mellitus and hypertension. Endocrinol Metab Clin North Am. 2014:43(1):103-22.

28. lepsen EW, Lundgren J, Dirksen C, Jensen J-EB, Pedersen O, Hansen T, Madsbad S, Holst JJ, Torekov SS. Treatment with a GLP-1 receptor agonist diminishes the decrease in free plasma leptin during maintenance of weight loss. Int J Obes. 2015;39(5):834-41.

29. Torekov SS, Kipnes MS, Harley RE, Holst JJ, Ehlers MR. Dose response of subcutaneous GLP-1 infusion in patients with type 2 diabetes. Diabetes Obes Metab. 2011;13(7):639-43.

30. Torekov SS, Holst JJ, Ehlers MR. Dose response of continuous subcutaneous infusion of recombinant glucagon-like peptide-1 in combination with metformin and sulphonylurea over 12 weeks in patients with type 2 diabetes mellitus. Diabetes Obes Metab. 2014;16(5):451-6.

31. Ettehad D, Emdin CA, Kiran A, Anderson SG, Callender T, Emberson $J$, et al. Blood pressure lowering for prevention of cardiovascular disease and death: a systematic review and meta-analysis. Lancet. 2016:387(10022):957-67.

32. Heerspink HJL, Ninomiya T, Zoungas S, de Zeeuw D, Grobbee DE, Jardine MJ, et al. Effect of lowering blood pressure on cardiovascular events and mortality in patients on dialysis: a systematic review and meta-analysis of randomised controlled trials. Lancet (London, England). 2009;373(9668):1009-15.

33. Yuasa S, Sato K, Furuki T, Minamizawa K, Sakai H, Numata Y, et al. Primary care-based investigation of the effect of sitagliptin on blood pressure in hypertensive patients with type 2 diabetes. J Clin Med Res. 2017;9(3):188-92.

34. Foley JE, Evans M, Schweizer A. Blood pressure and fasting lipid changes after 24 weeks' treatment with vildagliptin: a pooled analysis in $>2,000$ previously drug-naïve patients with type 2 diabetes mellitus. Vasc Health Risk Manag. 2016;12:337-40.
35. Mistry GC, Maes AL, Lasseter KC, Davies MJ, Gottesdiener KM, Wagner $J A$, et al. Effect of sitagliptin, a dipeptidyl peptidase-4 inhibitor, on blood pressure in nondiabetic patients with mild to moderate hypertension. J Clin Pharmacol. 2008;48(5):592-8.

36. Htike ZZ, Zaccardi F, Papamargaritis D, Webb DR, Khunti K, Davies MJ. Efficacy and safety of glucagon-like peptide-1 receptor agonists in type 2 diabetes: a systematic review and mixed-treatment comparison analysis. Diabetes Obes Metab. 2017;19(4):524-36.

37. Gerstein HC, Colhoun HM, Dagenais GR, Diaz R, Lakshmanan M, Pais $P$, et al. Dulaglutide and cardiovascular outcomes in type 2 diabetes (REWIND): a double-blind, randomised placebo-controlled trial. Lancet. 2019;394(10193):121-30.

38. Scirica BM, Bhatt DL, Braunwald E, Steg PG, Davidson J, Hirshberg B, et al. Saxagliptin and cardiovascular outcomes in patients with type 2 diabetes mellitus. N Engl J Med. 2013;369(14):1317-26.

39. White WB, Cannon CP, Heller SR, Nissen SE, Bergenstal RM, Bakris GL, et al. Alogliptin after acute coronary syndrome in patients with type 2 diabetes. N Engl J Med. 2013;369(14):1327-35.

40. Green JB, Bethel MA, Armstrong PW, Buse JB, Engel SS, Garg J, et al. Effect of sitagliptin on cardiovascular outcomes in type 2 diabetes. N Engl J Med. 2015;373(3):232-42.

41. Nyström T, Gutniak MK, Zhang Q, Zhang F, Holst JJ, Ahrén B, et al. Effects of glucagon-like peptide-1 on endothelial function in type 2 diabetes patients with stable coronary artery disease. Am J Physiol Metab. 2004;287(6):E1209-15.

42. Nyström T, Gonon AT, Sjöholm A, Pernow J. Glucagon-like peptide-1 relaxes rat conduit arteries via an endothelium-independent mechanism. Regul Pept. 2005;125(1-3):173-7.

43. Mudau M, Genis A, Lochner A, Strijdom H. Endothelial dysfunction: the early predictor of atherosclerosis. Cardiovasc J Afr. 2012;23(4):222-31.

44. Goud A, Zhong J, Peters M, Brook RD, Rajagopalan S. GLP-1 agonists and blood pressure: a review of the evidence. Curr Hypertens Rep. 2016;18(2):16.

45. Vincent MA, Clerk LH, Lindner JR, Klibanov AL, Clark MG, Rattigan S, et al. Microvascular recruitment is an early insulin effect that regulates skeletal muscle glucose uptake in vivo. Diabetes. 2004;53(6):1418-23.

46. Lambadiari V, Pavlidis G, Kousathana F, Varoudi M, Vlastos D, Maratou E, et al. Effects of 6-month treatment with the glucagon like peptide-1 analogue liraglutide on arterial stiffness, left ventricular myocardial deformation and oxidative stress in subjects with newly diagnosed type 2 diabetes. Cardiovasc Diabetol. 2018;17(1):8.

47. Ecobici M, Stoicescu C. Arterial stiffness and hypertension—which comes first? Maedica (Buchar). 2017;12(3):184-90.

48. Ishikawa S, Shimano M, Watarai M, Koyasu M, Uchikawa T, Ishii H, et al. Impact of sitagliptin on carotid intima-media thickness in patients with coronary artery disease and impaired glucose tolerance or mild diabetes mellitus. Am J Cardiol. 2014;1 14(3):384-8.

49. Kishimoto S, Kinoshita Y, Matsumoto T, Maruhashi T, Kajikawa M, Matsui S, et al. Effects of the dipeptidyl peptidase 4 inhibitor alogliptin on blood pressure in hypertensive patients with type 2 diabetes mellitus. Am J Hypertens. 2019;32(7):695-702.

50. Ramírez E, Picatoste B, González-Bris A, Oteo M, Cruz F, Caro-Vadillo A, et al. Sitagliptin improved glucose assimilation in detriment of fatty-acid utilization in experimental type-II diabetes: role of GLP-1 isoforms in Glut4 receptor trafficking. Cardiovasc Diabetol. 2018;17(1):12.

51. Zhang X, Zhang Z, Yang Y, Suo Y, Liu R, Qiu J, et al. Alogliptin prevents diastolic dysfunction and preserves left ventricular mitochondrial function in diabetic rabbits. Cardiovasc Diabetol. 2018;17(1):160.

52. Ferreira JP, Girerd N, Bozec E, Machu JL, Boivin J-M, London GM, et al. Intima-media thickness is linearly and continuously associated with systolic blood pressure in a population-based cohort (STANISLAS cohort study). J Am Heart Assoc. 2016;5(6):e003529.

53. Lalande S, Johnson DB. Diastolic dysfunction: a link between hypertension and heart failure. Drugs Today. 2008;44(7):503.

54. Kushima H, Mori Y, Koshibu M, Hiromura M, Kohashi K, Terasaki M, et al. The role of endothelial nitric oxide in the anti-restenotic effects of liraglutide in a mouse model of restenosis. Cardiovasc Diabetol. 2017;16(1):122.

55. Wong BW, Marsch E, Treps L, Baes M, Carmeliet P. Endothelial cell metabolism in health and disease: impact of hypoxia. EMBO J. 2017;36(15):2187-203. 
56. Chen $Y$, Zhang $X$, He J, Xie Y, Yang Y. Delayed administration of the glucagon-like peptide 1 analog liraglutide promoting angiogenesis after focal cerebral ischemia in mice. J Stroke Cerebrovasc Dis. 2018;27(5):1318-25.

57. Yoshihara M, Akasaka H, Ohnishi H, Miki T, Furukawa T, Yuda S, et al. Glucagon-like peptide-1 secretory function as an independent determinant of blood pressure: analysis in the Tanno-Sobetsu study. PLoS ONE. 2013;8(7):e67578.

58. Piotrowski K, Becker M, Zugwurst J, Biller-Friedmann I, Spoettl G, Greif M, et al. Circulating concentrations of GLP-1 are associated with coronary atherosclerosis in humans. Cardiovasc Diabetol. 2013;12(1):117.

59. Bak MJ, Wewer Albrechtsen NJ, Pedersen J, Knop FK, Vilsbøll T, Jørgensen $\mathrm{NB}$, et al. Specificity and sensitivity of commercially available assays for glucagon-like peptide-1 (GLP-1): implications for GLP-1 measurements in clinical studies. Diabetes Obes Metab. 2014;16(11):1155-64.

60. Orskov C, Rabenhøj L, Wettergren A, Kofod H, Holst JJ. Tissue and plasma concentrations of amidated and glycine-extended glucagon-like peptide I in humans. Diabetes. 1994;43(4):535-9.

61. Clarke SJ, Pettit S, Giblett JP, Zhao T, Kydd AC, Albrechtsen NJW, et al. Effects of acute GLP-1 infusion on pulmonary and systemic hemodynamics in patients with heart failure: a pilot study. Clin Ther 2019;41(1):118-27.
62. Smits MM, Tonneijck L, Muskiet MHA, Hoekstra T, Kramer MHH, Diamant $M$, et al. Heart rate acceleration with GLP-1 receptor agonists in type 2 diabetes patients: an acute and 12-week randomised, double-blind placebo-controlled trial. Eur J Endocrinol. 2017;176(1):77-86.

63. Monnard CR, Fellay B, Scerri I, Grasser EK. Substantial inter-subject variability in blood pressure responses to glucose in a healthy, non-obese population. Front Physiol. 2017;8:507.

64. Grasser EK, Dulloo A, Montani J-P. Cardiovascular responses to the ingestion of sugary drinks using a randomised cross-over study design: does glucose attenuate the blood pressure-elevating effect of fructose? $\mathrm{Br} J$ Nutr. 2014;112(2):183-92.

65. Brown CM, Dulloo AG, Yepuri G, Montani J-P. Fructose ingestion acutely elevates blood pressure in healthy young humans. Am J Physiol Integr Comp Physiol. 2008;294(3):R730-7.

\section{Publisher's Note}

Springer Nature remains neutral with regard to jurisdictional claims in published maps and institutional affiliations.
Ready to submit your research? Choose BMC and benefit from:

- fast, convenient online submission

- thorough peer review by experienced researchers in your field

- rapid publication on acceptance

- support for research data, including large and complex data types

- gold Open Access which fosters wider collaboration and increased citations

- maximum visibility for your research: over $100 \mathrm{M}$ website views per year

At BMC, research is always in progress.

Learn more biomedcentral.com/submissions 